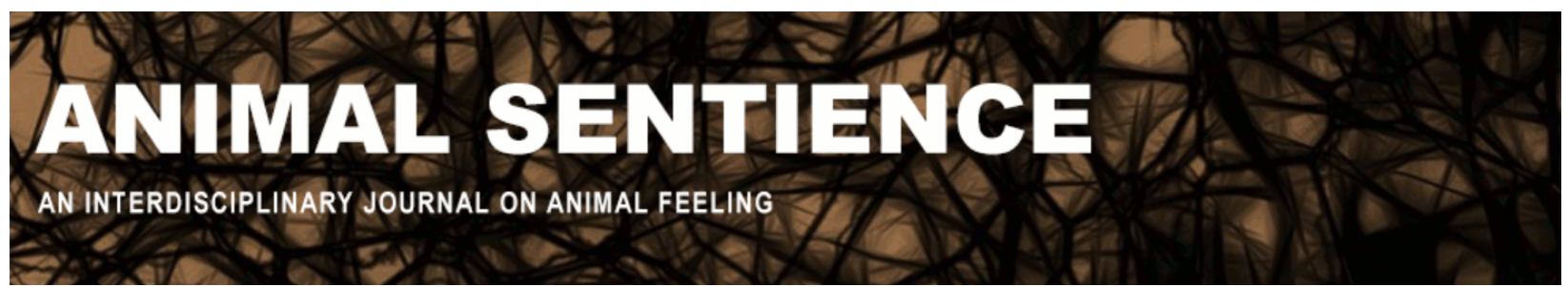

Manzotti, Riccardo (2018) The human nervous system is not the gold standard for pain. Animal Sentience 21(12)

DOI: $10.51291 / 2377-7478.1355$

Date of submission: 2018-07-01

Date of acceptance: 2018-07-03

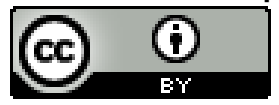

This article has appeared in the journal Animal

Sentience, a peer-reviewed journal on animal

cognition and feeling. It has been made open access,

free for all, by WellBeing International and deposited

in the WBI Studies Repository. For more information,

please contact

wbisr-info@wellbeingintl.org.

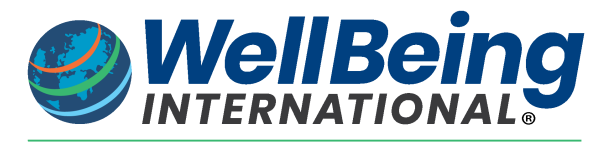

SOLUTIONS FOR PEOPLE, ANIMALS AND ENVIRONMENT 


\title{
The human nervous system is not the gold standard for pain
}

Commentary on Sneddon et al. on Sentience Denial

\author{
Riccardo Manzotti \\ Department of Psychology \\ IULM University
}

\begin{abstract}
The basis of pain could be the causal nexus between one's phylogenetic/ontogenetic history and one's behavior. It might turn out that the neural implementation is immaterial to the instantiation of pain. Widely different neural structures may token the same pain-type, and nearly identical neural structures may token different types.
\end{abstract}

Riccardo Manzotti is professor of psychology at IULM University (Milan). He is the author of more than fifty papers on the basis of consciousness. His main area of research is the physical basis of consciousness - what is consciousness in the physical world? He endorses a radical externalist framework for consciousness that goes beyond embodied cognition and enactivism. Website

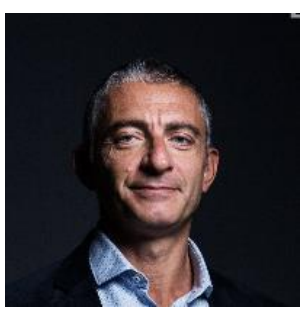

Sneddon et al. (2018) present a convincing rebuttal of various papers skeptical of fish pain (Stevens 2016; Diggles 2017; Key 2017). Sneddon makes a very convincing case, but a broader statement can and should be defended. Looking for similarity with human-like neural structures is a methodological error caused by covert human chauvinism and anthropocentrism. Anatomical distance from human neural structures is not a relevant criterion for pain sentience unless mind-brain identity (and thus pain-human-brain identity) is assumed to be true. So far, this has never been empirically demonstrated. There is no evidence that human neural structures are the sufficient (let alone necessary) basis of pain. There is no reason to think that pain does not occur when pain-avoidance behavior occurs in other biological agents with different neural structure.

The skeptics' objections (and to some extent, Sneddon et al.'s rebuttals) are all based on the assumption that the gold standard for pain sentience is the human-mammalian neural system. On this basis, they compare taxa or lament the absence of mammalian neural features such as the endocortical-thalamic connections or the amygdala (Rose 2002; Woodruff 2017). Sneddon et al. also seem to share the belief that distance from the human neural system is a useful measure: "phylogenetic distance from humans", "fish are more diverse than mammals". Yet, we have no reason to believe that only mammal-like animals feel pain.

If mind-brain supervenience is not assumed as a dogma, other views will be worthy of consideration, such as enactivism, externalism (Froese \& Fuchs 2012; Honderich 2014; O'Regan 2012; Rockwell 2005), or even more radical hypotheses. Elsewhere I have considered whether phenomenal experience is identical to external properties and objects (Manzotti 2017). The basis of pain could be the causal nexus between one's phylogenetic/ontogenetic history and one's behavior. It might turn out that the neural implementation is immaterial to the instantiation of pain. Widely different neural structures may token the same pain-type, and nearly identical neural structures may token different types. This is not a resurgence of 
functional multiple realizability, because actual environmental causes are mandatory. A fish or any other animal that exhibits pain-avoidance because it has the right phylogenetic/ontogenetic history is likely to have all that is required for pain. Pain would supervene on the environment-body-behavior causal nexus rather than on the internal neural machinery. There is no evidence that an animal that shows pain-avoidance does not feel pain, no matter what neural structure is involved. The precautionary principle stands strong and should be enforced.

\section{References}

Froese, T., \& Fuchs, T. (2012). The extended body: A case study in the neurophenomenology of social interaction. Phenomenology and the Cognitive Sciences, 11(2), 205-235.

Honderich, T. (2014). Actual Consciousness. London: Oxford University Press.

Manzotti, R. (2017). The Spread Mind. Why Consciousness and the World Are One. New York: OR Books.

O'Regan, K. J. (2012). How to build a robot that is conscious and feels. Minds and Machines, 22(2), 117-136.

Rockwell, T. (2005). Neither Brain nor Ghost. Cambridge, MA: MIT Press.

Sneddon, L. U., Lopez-Luna, J., Wolfenden, D. C. C., Leach, M. C., Valentim, A. M., Steenbergen, P. J., Bardine, N., Currie, A. D., Broom, D. M., \& Brown, C. (2018). $\underline{\text { Fish }}$ sentience denial: Muddying the waters. Animal Sentience 21(1). 


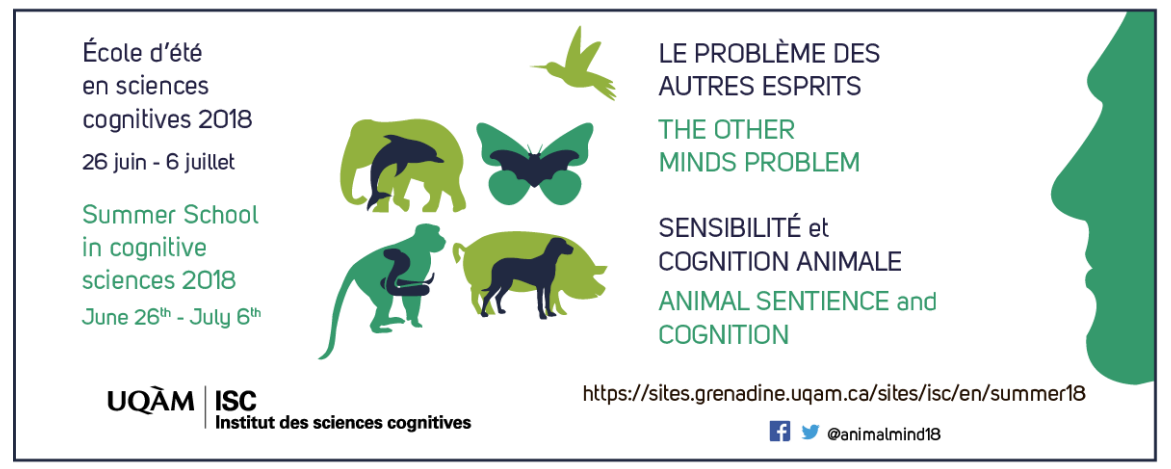

ISC 2018 Summer School in Cognitive Sciences

June 26 - July 6, 2018
Montreal (Canada)
The Other Minds Problem:
Animal Sentience and
Cognition

Overview. Since Descartes, philosophers know there is no way to know for sure what — or whether — others feel (not even if they tell you). Science, however, is not about certainty but about probability and evidence. The 7.5 billion individual members of the human species can tell us what they are feeling. But there are 9 million other species on the planet (20 quintillion individuals), from elephants to jellyfish, with which humans share biological and cognitive ancestry, but not one other species can speak: Which of them can feel — and what do they feel? Their human spokespersons - the comparative psychologists, ethologists, evolutionists, and cognitive neurobiologists who are the world's leading experts in "mindreading" other species - will provide a sweeping panorama of what it feels like to be an elephant, ape, whale, cow, pig, dog, chicken, bat, fish, lizard, lobster, snail: This growing body of facts about nonhuman sentience has profound implications not only for our understanding of human cognition, but for our treatment of other sentient species

\section{LIVE VIDEOS <---> ARCHIVED VIDEOS <---> BLOG DISCUSSION}

Gregory Berns: Decoding the Dog's Mind with Awake Neuroimaging

Gordon Burghardt: Probing the Umwelt of Reptiles

Jon Sakata: Audience Effects on Communication Signals

PANEL 1: Reptiles, Birds and Mammals

WORKSHOP 1: Kristin Andrews: The "Other" Problems:

Mind, Behavior, and Agency

Sarah Brosnan: How Do Primates Feel About Their Social Partners?

Alexander Ophir: The Cognitive Ecology of Monogamy

Michael Hendricks: Integrating Action and Perception in a Small Nervous System

PANEL 2: Primates, Voles and Worms

WORKSHOP 2: Jonathan Birch: Animal Sentience and the Precautionary Principle

Malcolm Maclver: How Sentience Changed After Fish Invaded Land 385 Million Years Ago

Sarah Woolley: Neural Mechanisms of Preference in Female Songbird Simon Reader: Animal Social Learning: Implications for Understanding Others

PANEL 3: Sea to Land to Air

WORKSHOP 3: Steven M. Wise: Nonhuman Personhood

Tomoko Ohyama: Action Selection in a Small Brain (Drosophila Maggot)

Mike Ryan: "Crazy Love": Nonlinearity and Irrationality in Mate Choice

Louis Lefebvre: Animal Innovation: From Ecology to Neurotransmitters PANEL 4: Maggots, Frogs and Birds: Flexibility Evolving SPECIAL EVENT: Mario Cyr: Polar Bears

Colin Chapman: Why Do We Want to Think People Are Different?

Vladimir Pradosudov: Chickadee Spatial Cognition

Jonathan Balcombe: The Sentient World of Fishes

PANEL 5: Similarities and Differences

WORKSHOP 5 (part 1): Gary Comstock: $\underline{\text { A Cow's Concept }}$

of Her Future

WORKSHOP 5 (part 2): Jean-Jacques Kona-Boun:

Physical and Mental Risks to Cattle and Horses in Rodeos
Joshua Plotnik: Thoughtful Trunks: Application of Elephant Cognition for Elephant Conservation

Lori Marino: Who Are Dolphins?

Larry Young: The Neurobiology of Social Bonding, Empathy and Social Loss in Monogamous Voles

Panel 6: Mammals All, Great and Small WORKSHOP 6: Lori Marino: The Inconvenient Truth About Thinking Chickens

Frantisek Baluska \& Stefano Mancuso: What a Plant Knows and Perceives

Arthur Reber: A Novel Theory of the Origin of Mind: Conversations With a Caterpillar and a Bacterium

PANEL 7: Microbes, Molds and Plants

WORKSHOP 7: Suzanne Held \& Michael Mendl: Pig Cognition and Why It Matters

James Simmons: What Is It Like To Be A Bat?

Debbie Kelly: Spatial Cognition in Food-Storing

Steve Phelps: Social Cognition Across Species

PANEL 8: Social Space

WORKSHOP 8: Alanna Devine \& Sophie Gaillard: Does the Law Protect Animals?

Lars Chittka: The Mind of the Bee

Reuven Dukas: Insect Emotions: Mechanisms and Evolutionary Biology

Adam Shriver: Do Human Lesion Studies Tell Us the Cortex is Required for Pain Experiences?

PANEL 9: The Invertebrate Mind

WORKSHOP 9: Delcianna Winders: Nonhuman Animals in Sport and Entertainment: Legal Aspects

Carel ten Cate: Avian Capacity for Categorization and Abstraction Jennifer Mather: Do Squid Have a Sense of Self?

Steve Chang: Neurobiology of Monkeys Thinking About Other Monkeys PANEL 10: Others in Mind WORKSHOP 10: The Legal Status of Sentient Nonhuman Species (Alain Roy, Nicolas Morello, Delcianna Winders) 